\title{
ASSESS DIFFERENT FORMS OF DOMESTIC VIOLENCE DURING PREGNANCY AND MATERNAL OUTCOME
}

\author{
Amal Dawod Kamal ${ }^{1}$, Amen Mustafa ${ }^{2}$, Ahmed Ramadan ${ }^{2}$, Mohamed Rashad $^{2}$, Bedor fathey $^{2}$, \\ Mustafa Mohammed ${ }^{2}$, Livana $\mathbf{P H}^{3}$ \\ ${ }^{1}$ Lecturer of maternity and new born health nursing department, Faculty of nursing Cairo university, \\ Egypt 11562 \\ ${ }^{2}$ Faculty of nursing Cairo university, Egypt 11562 \\ ${ }^{3}$ Kendal College of Health Science, Jln Laut 31A Kendal, Central Java, Indonesia 51311 \\ *dawod_m3@yahoo.com
}

\begin{abstract}
Domestic violence is Violence during pregnancy as violence or threat of physical, sexual or psychological (emotional) violence against pregnant women. The present study aims to-: Assess different forms of violence that women are exposed to by their partners during pregnancy Explore consequences of domestic violence on pregnant women out come. A descriptive exploratory research design was adopted in this study to achieve the stated aim. Postpartum units were selected from at El-manial maternity hospital, this hospital is a university-affiliated hospital which providing free health care service topostpartum women and their newborn. Structured interviewing questionnaire, domestic violence assessment tool, and maternal pregnancy outcome tool. Indicated that age of woman ranged from 15-45 years with mean $31.65+/-6.79 .42 \%$ of sample living in urban areas, while $58 \%$ living in rural areas. Percentage of domestic violence according to total domestic violence scale $82 \%$ suffer from different type of domestic violence, regarding the maternal outcome $20 \%$ of cases have bleeding during delivery , 24\% exposed to premature rapture of membrane, and $30 \%$ exposed to menstrual problems. Women are exposed to different forms of domestic violence during pregnancy. These forms of violence have an impact on the pregnancy outcomes such as abortions, bleeding during delivery, premature rapture of membrane, and menstrual problems others.
\end{abstract}

Keywords: domestic violence; maternal outcome

\begin{tabular}{|c|c|c|}
\hline $\begin{array}{c}\text { First Received } \\
28 \text { June } 2020 \\
\end{array}$ & $\begin{array}{c}\text { Revised } \\
18 \text { August } 2020\end{array}$ & $\begin{array}{c}\text { Accepted } \\
28 \text { August } 2020\end{array}$ \\
\hline $\begin{array}{c}\text { Final Proof Received } \\
29 \text { August } 2020 \\
\end{array}$ & & $\begin{array}{l}\text { Published } \\
31 \text { August } 2020\end{array}$ \\
\hline \multicolumn{3}{|c|}{$\begin{array}{l}\text { How to cite (in APA style) } \\
\text { Kamal, A., Mustafa, A., Ramadan, A., Rashad, M., Fathey, B., Mohammed, M., \& PH, L. (2020). Assess } \\
\text { Different Forms of Domestic Violence During Pregnancy and Maternal Outcome. Indonesian Journal of } \\
\text { Global Health Research, 2(3), 231-244. }\end{array}$} \\
\hline
\end{tabular}

\section{INTRODUCTION}

Violence during pregnancy as violence or threat of physical, sexual or psychological (emotional) violence against pregnant women. In the literature review it was observed prevalence from $0.9 \%$ to $20.1 \%$."The Pan -American Health organization (PAHO) defines"Domestic violence against women is one of the most pervasive abuses of human rights in the world that lie in the spheres of those who are interested in the study of women's health and her rights. Violence against women is the barrier of women's empowerment and hinders the equal participation in society. However, they often go unnoticed and undocumented and therefore unresolved. Violence during pregnancy may threaten not only a woman well-being but that of her unborn child. Among women who had ever been pregnant six percent were hit, slapped, kicked or subjected to some other form of physical violence (Bailey, 2012). 
The World Health Organization (WHO) showed that, the prevalence of physical or sexual, or both type of violence varied from fifteen percent to seventy one percent in different countries. (WHO 2012) Psychological problems and complications of pregnancy are some of the health consequences that result from violence inflicted on pregnant women by their intimate male partners (WHO, 2011).

Urquia et al., (2011), was reported that UN attention has been given to domestic violence during pregnancy as global public health problem due to its adverse health consequences. An understanding of the effect of a partner's violence against a pregnant woman could have important reproductive health implications with early identification. It could also help in shaping future intervention programs. Pregnancy provides an opportunity to screen for domestic violence since pregnant women make routine antenatal.

On the other hand, violence against women perpetrated by husbands occurs in every society, but its prevalence and tolerance vary from country to country. Studies demonstrate that violence during pregnancy is more common in developing countries than developed countries and the consequence of domestic violence during pregnancy ranges from financial hardships and decreased intimacy to high rates of maternal and neonatal morbidity and mortality (Devries et al., 2010).

Violence during pregnancy had a higher rate of preterm labor and intrauterine growth retardation than women without a history of violence; also domestic violence during pregnancy is associated with adverse pregnancy outcomes such as low birth weight, spontaneous abortion, bleeding during pregnancy, and higher neonatal deaths (Berenson et al., 2010).

Violence against pregnant women is a problem present in all social strata of the world. over time its predominant presentation was domestic, generated in part repetitive patterns of behavior, generation to generation, making it a growing phenomenon most of the violent acts have as a consequence injuries, mental disorders, reproductive disorders , sexually transmitted diseases and other problems (WHO 2012).

Domestic violence against women has many forms including Physical abuse such as punching, slapping, hitting, biting, pinching, kicking, pulling hair out, pushing, shoving, burning, and strangling. Psychological abuse includes threatening, insulting, humiliating, isolating or neglecting. Sexual abuse of women includes using force, intimidating them to perform sexual acts, or having sex with them when they don't want to have sex"agyemang;et-al;2014" and Elhamid;ibrahim;sayed\&hagras;"2015"

Complication of domestic violence against women leads to far-reaching physical and psychological consequences on women health such as injury, headaches, permanent disabilities, asthma, irritable bowel syndrome, gynecological problems, unwanted pregnancy and self-injurious behaviors. While psychological health outcomes includes depression, fear, anxiety, low self-esteem, sexual dysfunction, eating disorders, sleeping problems, post-traumatic stress disorder, panic attacks, strained family relationships and an inability to adequately respond to the needs of their children (mostafa;2013;\&Bewley;etal.2014). 
Pregnancy doesn't prevent women from exposure to violence; although it has serious complications for their health and fetus. Violence against pregnant women has a host of negative reproductive health outcomes, including more sexually transmitted infections, higher rates of unintended pregnancy, limited utilization of prenatal care, and low birth weight ,the health effect can last for years, and sometimes consist permanent physical or mental disabilities and even death .on the other hand in health systems don't have the information or the necessary expertise to handle such problems, it doesn't have the necessary information to which patients should be referred submit such conflicts (Flach et al., 2011).

In Egypt, the results of a survey conducted found that about one third of women are physically abused by their husbands at some time in their live. In Egypt, particularly violence against women is rooted in the subordinate position of women in the family and society "The National Demographic Health Survey in 2005". Some women life situation have been described as domestic violence related factors: low socioeconomic status, low level of social support, being an African descent and young. highlighted the magnitude of the subject as a world damage, it is necessary to consider the association of social determinants in the revelation incidence and prevalence indexes, the fact is ratified in the extension numbers when compared between developing and developed cycle ( Hansson, 2014). Based on this understanding, the purposes of present study outl). ineto identify the effect of domestic violence on pregnancy outcomes at university maternity hospital.

Domestic violence is a serious problem around the world. It violates the fundamental human rights of women and often results in serious injury or death; one in every three women in the world has experienced sexual, physical, emotional or other abuse in her lifetime. Violence against women, committed by an intimate partner, is an important public health and human rights issue. In recent years, attention has focused also on intimate partner violence during pregnancy due to its

Prevalence, adverse health consequences and intervention potential. So, an understanding of the effect of a partner's violence against a pregnant woman could have important reproductive health implications with early identification. Pregnancy provides an opportunity to screen for domestic violence since pregnant women make routine visits during this period. Therefore, it is critical to explore the impact of violence on pregnancy outcomes in pregnant women.

Consequently, this study will help community health nurse to acquire data base about domestic violence against women and its consequences on family health as a community health issue and provide more reliable information to professionals in medical, social and nursing fields. Information from this study will also divert the attention of policy makers to consider laws and regulations in protecting the women rights. Initiation of educational programmers for people about domestic violence against women, furthermore, the current research will be carried out in an attempt to describe to what extent women and their children are at risk of different health consequence from violence. It might also generate an attention and motivation for further researches in this area of study. The aim of this study was to identify the type of domestic violence and their effect on pregnancy outcomes assess the outcome of violence on pregnant women. 


\section{METHOD}

Descriptive exploratory design was adopted in this study was to assess the type and affect the outcome of violence on pregnant women. it is type of research design used to describe characteristics of a population or phenomenon that has not been clearly defined (Shields, Patricia, \&Rangarjan, 2013). To fulfill the aim of the study two postpartum units were selected from (department 10\&21) at El-manial maternity hospital, this hospital is a university-affiliated hospital which providing free health care service to postpartum women and their newborn. The postpartum unit at emergency department (section10), which includes two rooms which contain 30 beds, receives approximately 10 beds for caesarean section (CS) and 20 beds for vaginal delivery (VD). While in section 21, it includes 30 beds for CS women only. According to annual statistical of El manial maternity hospital statistics 2016, both postpartum unit receive approximately 8244 women delivered by CS and 10912 delivered by VD.

Purposive sample of 50 postpartum women were recruited for the current study during November and December 2017-at El Manial University Hospitalaccording to the following inclusion criteria, pregnant women who exposed to domestic violence during pregnancy and free from any medical disease. The tools which are used to collect data in the current study include, structured interviewing questionnaire, maternal assessment tools, domestic violence assessment tools, and regnancy out come tool.

Structured interviewing questionnaire (appendix A) was designed by the investigator, it include 13 items to elicit data related to: socio-demographic characteristics which contained data related to postpartum women and data related to her husband. Sociodemographic data: included data related to the assessment of risk factor behind abusing wife, it contain age, education, job, residence (rural or urban), living separate home or with big family, the health status, income, maternal status (one or more wives), expenditure (support one or more families or non) and addiction for the husband.

Maternal assessment tool (appendix B) included past obstetric history: which contained parity, gravity, mood of previous delivery, complication of previous pregnancies, date of last delivery, number of abortion, number of preterm and the type of previous lactation. Maternal assessment tools. Domestic violence assessment tools It develop by the researcher after massive literature reviewing related to violence it include 4 scales : a)physical victimization sub-scale (hitting, slapping); b)psychological/emotional victimization sub-scale(constant, criticism or humiliation, abusive language, threatening with object ignoring, etc); c)sexual victimization sub-scale:(forcing to unwanted sexual intercourse, ignoring her desire, demanding unwanted sexual acts ect); d)economical victimization sub-scale:(controlling her salary, refusing to work and support the family, demanding the partner sign over pay checks).

Measuring outcome of violence against Pregnant women (appendix c) was formulated to measure the out come of violence against pregnant women physical ,social and psychological during and after pregnancy and delivery such as premature labor ,pre eclamcia ,gestational diabetes, low birth weight, and the psychological status of the mother and her acceptance to the child and the father of the child , and problems facing her during delivery such as hemorrhage during delivery or post partum . 
Tools submitted to a panel of 5 experts in the fields of maternity nursing and psychiatric nursing to test the content validity. Modification carried out according to the panel judgment on clarity of sentences and appropriateness of content. An official permission is granted from the research ethical committee, and the vice dean of postgraduate study and research at faculty of nursing Cairo university, then official research permission was taken from the hospital administrator to collect data from postpartum women attending postpartum unit in both setting. All participant were informed about the purpose of the study and its importance in order to obtain their acceptance to share in the current study and ensuring that the study posed no risk or hazard on their lives

The researcher emphasized that participation in the study is entirely voluntary; no names were included in the questionnaire sheet. Anonymity and confidentiality were assured through coding the date, and informing them that the content of the tool will be used only for research purpose. every participant was informed that she has the right to withdraw from this study at any time without giving reason; this withdrawal will not affect the care she is receiving. Written consent was taken from the participant who accepted to be include in the study.

A total of $10 \%$ of the sample recruited for the pilot study according to the criteria of selection. The pilot study was carried out to test the items in the tools used in the current study: clarity of question, and time needed to answer the questions. Additionally, the pilot study carried out to examine the applicability of the study procedures, and identify any difficulties raised and needed to be handled before applying the study. The pilot sample was excluded from the actual study sample because of the modification of the tools.

An official permission to conduct the proposed study was obtained from the hospital administrators. As well, all participants and health care providers were informed orally about the purpose, importance and benefits of the study. Additional, they were aware that the investigator is students candidate at the Faculty of Nursing; Cairo University. Data was collected through a period of November and December 2017 on a total numbers of 50 postpartum women. A written approval had been obtained from the Director of the maternity Hospital at EL Manial University Hospital after explaining the purpose of the study. The investigator met the women at the postpartum unit's number (21), and obtained their acceptance to be recruited in the study, as well as to gain their cooperation; the investigator introduced herself to them and explained the nature and aim of the study, its importance, and its benefits.

Each postpartum woman was interviewed to collect data related to demographic characteristics such as; age, occupation, level of education (Appendix A) ...etc , and maternal profile sheetobstetric history such as parity, gravidity, number of living children, and violence assessment tools (Appendix B) and (Appendix c) ....etc. The investigator faced each woman, asked her questions in simple Arabic language and recorded each answer in the questionnaire sheet. The interview lasted for about 10 to 15 minutes. 
The Statistical Package for the Social Sciences (SPSS) software, version 20, was used for data entry and data analysis. Data management was done by coding and entering responses into computer. The investigator checked all data to avoid any discrepancies. Data were examined for coding and entering error. Data were stored in passwordprotected computer files which were accessed only by the investigator. Furthermore, backup files of the data were stored on a $\mathrm{CD}$ or another drive in a locked cabinet to prevent loss or corruption of data. Descriptive statistics were used to analyze the sample population. Mean, standard deviation, and frequency distribution were used. The majority of the study participants was immediately after post operative, and had severe pain and sometimes refused participation in the study. Additionally, the current project need more time than one semester.

\section{RESULTS}

The result will be presented in three main sections. Description of the sample and their husbands by their socio-demographic data as possible risk factor include age, education, occupation for women and their husband, residence, income, medical and obstetrical history will be presented in first section; patterns of domestic violence will be presented in second section .maternal outcome will be presented in the third section.

\section{Description of the sample and their husbands by their socio-demographic data}

The age of the pregnant women ranged between 15-40 years table (1) showed that the majority of the pregnant women (72\%)aged between 20-30 years old. In relation to level of education high percentage of the pregnant women $(56 \%)$ can read and write while $(8 \%)$ can't read and write ( figure, 1$)$. While $(36 \%)$ has university education. Also table 1 clarified that the majority of pregnant women $(58 \%)$ house wives while $(42 \%)$ working mothers. High percentage of them (58\%) living in rural areas and the remaining (42\%) living in urban areas (figure 1), while( figure 2) showed that distribution of pregnant women in relation to living status indicated that (40\%) live with husbands family, while (34\%) in separate flat while (26\%) with husband.

Table 1.

Socio Demographic Characteristics of Study Sample $(n=50)$

\begin{tabular}{lcc}
\hline \multicolumn{1}{c}{ Characteristics } & $\mathrm{f}$ & $\%$ \\
\hline Age & 2 & 4 \\
$15-20$ & 36 & 72 \\
$20-30$ & 12 & 24 \\
$30-40$ & & \\
\hline Education & 8 & 4 \\
Cant read \& write & 56 & 28 \\
Can read \& write & 36 & 18 \\
university & & \\
Job & 21 & 42 \\
Working & 29 & 58 \\
House wife & & \\
\hline
\end{tabular}


Table 2.

Socio Demographic Data of the Husband of the Pregnant Women

\begin{tabular}{lcc}
\hline \multicolumn{1}{c}{ Characteristics } & $\mathrm{f}$ & $\%$ \\
\hline Age & 42 & 84 \\
$20-40$ & 8 & 16 \\
$40-60$ & 21 & 42 \\
\hline Job & 28 & 56 \\
Free work & 1 & 2 \\
Worker & & \\
Don't work & 4 & 8 \\
\hline Education & 30 & 60 \\
Cant read \&write & 16 & 32 \\
Can read\& write & & \\
University & 12 & 24 \\
\hline Income & 27 & 54 \\
Daily & 11 & 22 \\
Monthly & & \\
Monthly \& extra salary & 46 & 82 \\
\hline Marital status & 4 & 10 \\
One wife & & 84 \\
Two wives & 5 & 6 \\
\hline Affording & 42 & 64 \\
Don't afford & 3 & 32 \\
Afford one family & & \\
Afford two family & 32 & \\
\hline Health & 16 & \\
Healthy & 2 & \\
Moderate & & \\
Ill & & \\
\hline & & \\
\hline & & \\
\hline
\end{tabular}

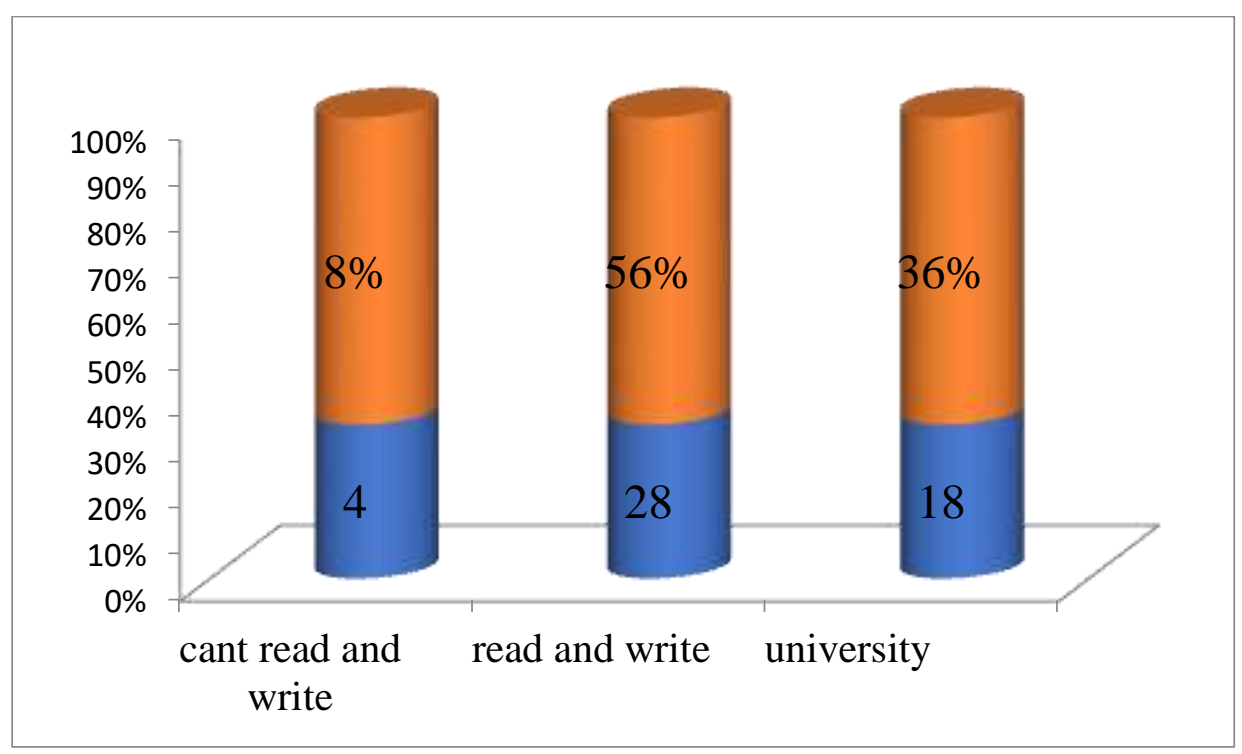

Figure 1. Level of Education Pregnant Women 


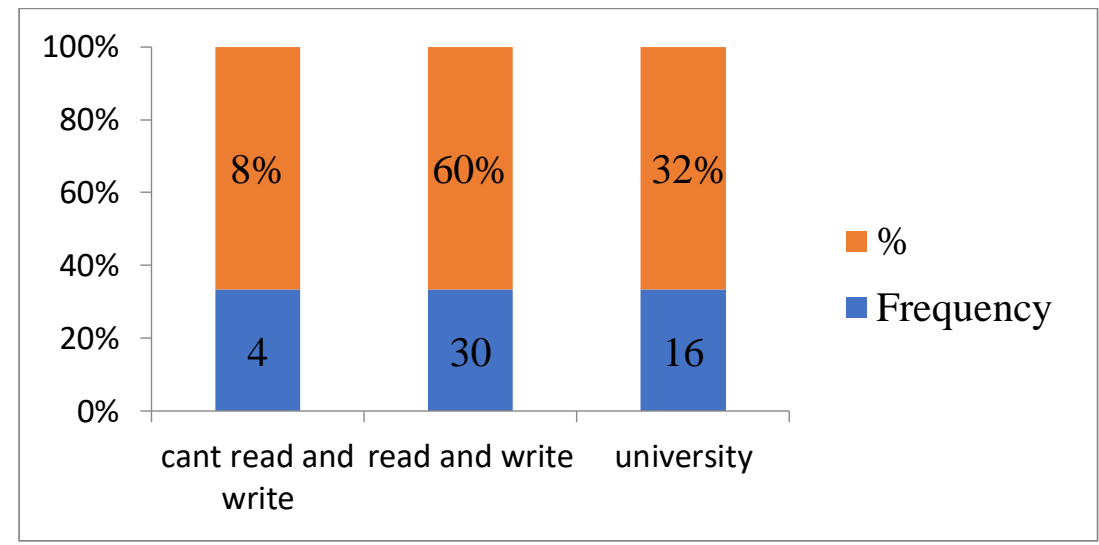

Figure 2. Husband level of education

Table 3.

Characteristics of Domestic Violence Studied Groups ( $\mathrm{n}=50)$

\begin{tabular}{lcc}
\hline \multicolumn{1}{c}{ Characteristics } & $\mathrm{f}$ & $\%$ \\
\hline Physical & 46 & 92 \\
Non & 4 & 8 \\
Mild & 0 & 0 \\
Moderate & 0 & 0 \\
Severe & & \\
Psychological & 31 & 62 \\
Non & 16 & 32 \\
Mild & 3 & 6 \\
Moderate & 0 & 0 \\
Severe & 35 & 70 \\
Non & & \\
Financial & 10 & 20 \\
Mild & 5 & 10 \\
Moderate & 0 & 0 \\
Severe & & \\
Sexual & 31 & 62 \\
Non & 15 & 30 \\
Mild & 4 & 8 \\
Moderate & 0 & 0 \\
Severe & & \\
& & \\
\hline
\end{tabular}

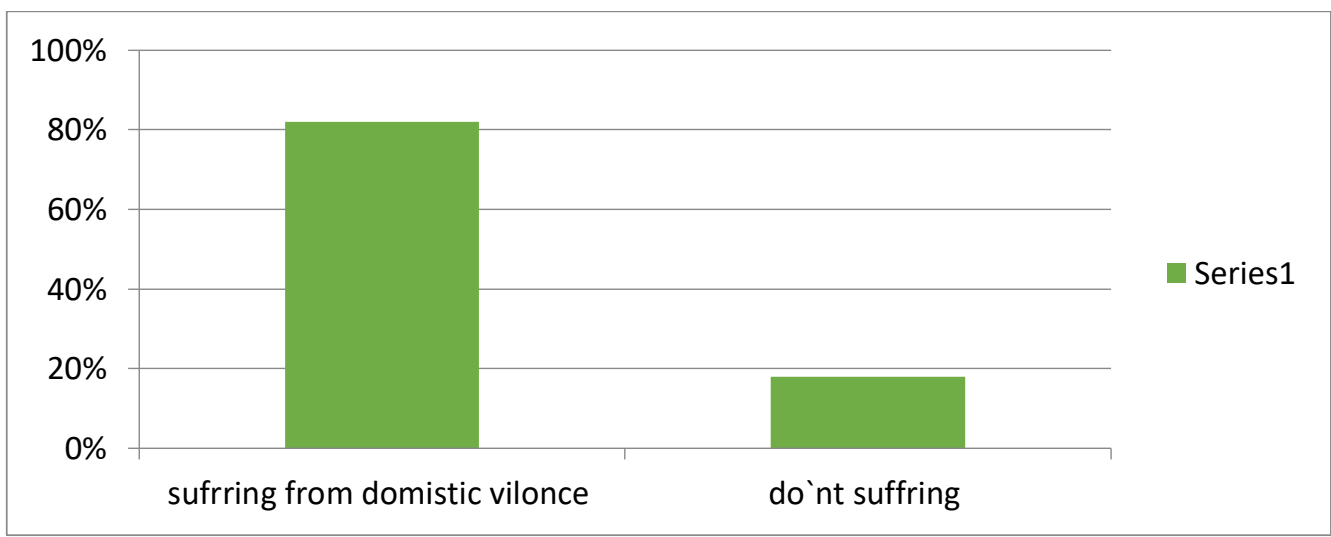

Figure 3. Different Type of Domestic Violence 
Table 4.

The Causes of Abuse Among the Study Sample ( $n=50)$

\begin{tabular}{lcccccccccc}
\hline Variable & \multicolumn{2}{c}{ Don't } & \multicolumn{2}{c}{ Rare } & \multicolumn{2}{c}{ Sometimes } & \multicolumn{2}{c}{ Repeated } & \multicolumn{2}{c}{ Always } \\
\hline Slap & 28 & 56 & 14 & 28 & 7 & 14 & 1 & 2 & 0 & 0 \\
\hline Throw On & 17 & 34 & 19 & 38 & 10 & 20 & 4 & 8 & 0 & 0 \\
\hline Push & 29 & 58 & 7 & 14 & 9 & 18 & 5 & 10 & 0 & 0 \\
\hline catch Cloth & 28 & 56 & 9 & 18 & 7 & 14 & 6 & 12 & 0 & 0 \\
\hline Kick Me & 38 & 76 & 8 & 16 & 3 & 6 & 1 & 2 & 0 & 0 \\
\hline Pinch Me & 29 & 58 & 12 & 24 & 6 & 12 & 3 & 6 & 0 & 0 \\
\hline Hit me & 25 & 50 & 14 & 28 & 6 & 12 & 3 & 6 & 2 & 4 \\
\hline Stifling Me & 40 & 80 & 7 & 14 & 1 & 2 & 2 & 4 & 0 & 0 \\
\hline Burn me & 41 & 82 & 5 & 10 & 2 & 4 & 1 & 2 & 1 & 2 \\
\hline Against Wall & 31 & 62 & 9 & 18 & 8 & 16 & 1 & 2 & 1 & 2 \\
\hline Sharp Things & 44 & 88 & 5 & 10 & 1 & 2 & 0 & 0 & 0 & 0 \\
\hline Ugly me & 27 & 54 & 11 & 22 & 11 & 22 & 1 & 2 & 0 & 0 \\
\hline Curse Me & 23 & 46 & 13 & 26 & 11 & 22 & 3 & 6 & 0 & 0 \\
\hline Spreader & 19 & 38 & 18 & 36 & 6 & 12 & 6 & 12 & 1 & 2 \\
\hline Ignoring & 19 & 38 & 17 & 34 & 4 & 8 & 7 & 14 & 3 & 6 \\
\hline Smash Things & 28 & 56 & 15 & 30 & 6 & 12 & 1 & 2 & 0 & 0 \\
\hline Prevent Friend & 20 & 40 & 20 & 40 & 8 & 16 & 2 & 4 & 0 & 0 \\
\hline Valued & 31 & 62 & 7 & 14 & 7 & 14 & 5 & 10 & 0 & 0 \\
\hline Criticize me & 26 & 52 & 12 & 24 & 7 & 14 & 5 & 10 & 0 & 0 \\
\hline Threaten Me & 24 & 48 & 13 & 26 & 7 & 14 & 4 & 8 & 2 & 4 \\
\hline ignore illness & 24 & 48 & 14 & 28 & 4 & 8 & 5 & 10 & 3 & 6 \\
\hline watch action & 18 & 36 & 14 & 28 & 6 & 12 & 11 & 22 & 1 & 2 \\
\hline Threaten Divorce & 28 & 56 & 11 & 22 & 3 & 6 & 4 & 8 & 4 & 8 \\
\hline harm family & 35 & 70 & 7 & 14 & 7 & 14 & 0 & 0 & 1 & 2 \\
\hline take Child & 31 & 62 & 10 & 20 & 6 & 12 & 3 & 6.0 & 0 & 0 \\
\hline ignore Speak & 25 & 50 & 16 & 32 & 2 & 4.0 & 6 & 12 & 1 & 2 \\
\hline Prevent Family & 25 & 50 & 14 & 28 & 9 & 18 & 2 & 4 & 0 & 0 \\
\hline Raping Me & 29 & 58 & 11 & 22 & 8 & 16 & 2 & 4 & 0 & 0 \\
\hline Illegal Relation & 37 & 74 & 8 & 16 & 4 & 8 & 1 & 2 & 0 & 0 \\
\hline Ignore Desire & 23 & 46 & 15 & 30 & 10 & 20 & 1 & 2 & 1 & 2 \\
\hline Cause Pain & 26 & 52 & 14 & 28 & 5 & 10 & 2 & 4 & 3 & 6 \\
\hline & & & & & & & & & & \\
\hline
\end{tabular}

Table 5.

Financial Causes of Abuse Among the Study Sample ( $n=50)$

\begin{tabular}{lcccccccccrr}
\hline \multicolumn{1}{c}{ Variable } & \multicolumn{2}{c}{ Don't } & \multicolumn{3}{c}{ Rare } & \multicolumn{3}{c}{ Sometimes } & Repeated & \multicolumn{2}{c}{ Always } \\
\hline Take Money & 35 & 70 & 8 & 16 & 4 & 8 & 3 & 6 & 0 & 0 \\
\hline Don't Provide Require & 31 & 62 & 10 & 20 & 4 & 8 & 4 & 8 & 1 & 2 \\
\hline Don't Give Money & 21 & 42 & 18 & 36 & 3 & 6 & 5 & 10 & 3 & 6 \\
\hline Take Properties & 32 & 64 & 11 & 22 & 1 & 2 & 5 & 10 & 1 & 2 \\
\hline Prevent Burning & 27 & 54 & 14 & 28 & 3 & 6 & 5 & 10 & 1 & 2 \\
\hline Prevent Greeting & 29 & 58 & 9 & 18 & 6 & 12 & 5 & 10 & 1 & 2 \\
\hline Expensive For Him Cheap & 29 & 58 & 10 & 20 & 4 & 8 & 6 & 12 & 1 & 2 \\
\hline Expensive Gifts For Him & 30 & 60 & 9 & 18 & 3 & 6 & 5 & 10 & 3 & 6 \\
\hline Cheap Even Bad & 31 & 62 & 8 & 16 & 7 & 14 & 4 & 8 & 0 & 0 \\
\hline
\end{tabular}


Table 6.

The Psychological Causes of Abuse Among the Study Sample $(\mathrm{n}=50)$

\begin{tabular}{|c|c|c|c|}
\hline \multicolumn{2}{|c|}{ Variabels } & $\mathrm{f}$ & $\%$ \\
\hline \multirow[t]{2}{*}{ Work Shortage } & Yes & 23 & 46 \\
\hline & No & 27 & 54 \\
\hline \multirow[t]{2}{*}{ Out Without Permission } & Yes & 37 & 74 \\
\hline & No & 13 & 26 \\
\hline \multirow[t]{2}{*}{ Don't Work } & Yes & 13 & 26 \\
\hline & No & 37 & 74 \\
\hline \multirow[t]{2}{*}{ His Illness } & Yes & 14 & 28 \\
\hline & No & 36 & 72 \\
\hline \multirow[t]{2}{*}{ Inter Family } & Yes & 27 & 54 \\
\hline & No & 23 & 46 \\
\hline \multirow[t]{2}{*}{ Much Burdens } & Yes & 27 & 54 \\
\hline & No & 23 & 46 \\
\hline \multirow[t]{2}{*}{ Aggressive } & Yes & 14 & 28 \\
\hline & No & 36 & 72 \\
\hline \multirow[t]{2}{*}{ Nervous } & Yes & 29 & 58 \\
\hline & No & 21 & 42 \\
\hline \multirow{2}{*}{ Provoke Him } & Yes & 27 & 54 \\
\hline & No & 23 & 46 \\
\hline
\end{tabular}

Table 7.

Association of Violence During Pregnancy on Pregnancy Outcomes

\begin{tabular}{lcccc}
\hline \multirow{2}{*}{ Outcome } & \multicolumn{2}{c}{ Yes } & \multicolumn{3}{c}{ No } \\
\cline { 2 - 5 } & $\mathrm{f}$ & $\%$ & $\mathrm{f}$ & $\%$ \\
\hline Loss of Weight before Delivery & 6 & 12 & 44 & $88 \%$ \\
\hline Diabetes During Pregnancy & 18 & 36 & 32 & $64 \%$ \\
\hline Hypertension During Pregnancy & 22 & $44 \%$ & 28 & $56 \%$ \\
\hline Bleeding During Delivery & 10 & $20 \%$ & 40 & $80 \%$ \\
\hline Long Period of Delivery & 18 & $36 \%$ & 32 & $64 \%$ \\
\hline Premature Rapture of Membrane & 12 & $24 \%$ & 38 & $76 \%$ \\
\hline Postpartum Hemorrhage & 7 & $14 \%$ & 43 & $86 \%$ \\
\hline Depression after Delivery & 27 & $54 \%$ & 23 & $46 \%$ \\
\hline Premature Labor & 16 & $32 \%$ & 34 & $68 \%$ \\
\hline Change in The Way of Dealing with the Child & 23 & $46 \%$ & 27 & $54 \%$ \\
\hline Low Birth Weight & 31 & $62 \%$ & 19 & $38 \%$ \\
\hline Loss of Weight after Delivery & 22 & $44 \%$ & 28 & $56 \%$ \\
\hline Abortion & 11 & $22 \%$ & 39 & $78 \%$ \\
\hline Ectopic Pregnancy & 3 & $6 \%$ & 47 & $94 \%$ \\
\hline Menstrual Problems & 15 & $30 \%$ & 35 & $70 \%$ \\
\hline Vaginal Problems & 14 & $28 \%$ & 36 & $72 \%$ \\
\hline Organ Distortion & 5 & $10 \%$ & 45 & $90 \%$ \\
\hline Suicide & 4 & $8 \%$ & 46 & $92 \%$ \\
\hline Loss Of Sexual Desire & 23 & $46 \%$ & 27 & $54 \%$ \\
\hline Fatigue And Hair Loss & 26 & $52 \%$ & 24 & $48 \%$ \\
\hline Hysterectomy & 0 & $0 \%$ & 50 & $100 \%$ \\
\hline
\end{tabular}

Regarding socio-demographic data of the husband of the pregnant women (table 2) clarified the following age found that $(84 \%)$ ringed between $20-40$ years old. Level of 
education high percentage $(60 \%)$ can read and write, $(32 \%)$ university education and $(8 \%)$ can not read and write. Occupation of husband $(56 \%)$ worker, $(42 \%)$ free work, $(2 \%)$ don't work. Health of husband (64\%) healthy, $32 \%)$ slightly sick, while $(4 \%)$ was critically ill. Number of wives of the husband was $(92 \%)$ one wife, while (8\%) two wives. Financial responsibility (84\%) afforded 1 family, while (10\%) didn't afford any family,(6\%)afforded two family. Addiction (56\%) cigarette smoking,(4\%)alcohol consumer, $(6 \%)$ drug abuse, $(34 \%)$ non smoker (figure 3 ).

\section{Patterns of Domestic Violence}

The result indicated that the majority of the study sample $82 \%$ suffer from different type of domestic violence (figure, 1 ). table 3 interpreted that $92 \%$ don't suffer from physical violence while $4 \%$ suffer from mild and mean of physical abuse $17.56+/-6.68,62 \%$ don't suffer from psychological violence, 32\% suffer from mild, $6 \%$ suffer from moderate psychological violence and mean of total psychological abuse $36.3+/-15.4$, $70 \%$ don't exposed to financial violence, $20 \%$ suffer from mild, $10 \%$ suffer from moderate financial violence and mean of financial abuse $15.74+/-8.24$, while $62 \%$ don't suffer from sexual violence, $30 \%$ suffer from mild, $8 \%$ from moderate. Table, 2 , 3, 4:-

\section{Represented Domestic Violence Outcome on Mothers}

Loss of weight before delivery $12 \%$ loss of weight while $88 \%$ not, $36 \%$ off the cases have diabetes during pregnancy while $64 \%$ not, $44 \%$ have hypertension during pregnancy, $20 \%$ of cases have bleeding during delivery, $36 \%$ exposed to long period of delivery, $24 \%$ exposed to premature rapture of membrane while $76 \%$ didn't exposed to premature rapture of membrane, $14 \%$ exposed to postpartum hemorrhage, the study shows that $54 \%$ of cases suffer from depression after delivery, $32 \%$ exposed to premature labor, $46 \%$ of cases suffer from change in the way of dealing with the child, $62 \%$ of the children born to these cases have low birth weight, $44 \%$ exposed to loss of weight after delivery, $22 \%$ of the cases exposed to abortion, $6 \%$ exposed to ectopic pregnancy, $30 \%$ exposed to menstrual problems, $28 \%$ exposed to vaginal problems, $10 \%$ exposed to organ distortion, $8 \%$ try to suicide, $46 \%$ exposed to loss of sexual desire after delivery, $52 \%$ exposed to fatigue and hair loss while, $100 \%$ not exposed to hysterectomy ( Table 5).

\section{DISCUSSION}

Domestic violence against women is an important neglected public health problem in the Egyptian community that needs multidisciplinary approach to understand its causes and plan effective preventive measures (Abd El Maqsoud, abunazal and dabbous 2011). Domestic violence is a big health problem when coupled with pregnancy where health risks may be amplified. Abuse during pregnancy withers physical or emotional produces many adverse physical and psychological effects for both the mother and the fetus (Ellis et al, 2011). So the aim of this study is to assess the maternal outcome of domestic violence.

A purposive sample of 50 postpartum women was selected to this study in certain criteria, age up to 45 years old with various level of socioeconomic status the institutions for which the pregnant woman were recruited from postpartum words at el manial maternity hospital Cairo university, data collected for 1 month from 10/11/2017 
to 10/12/2017. Visiting postpartum wards 3 times per weak and selecting cases according to inclusion criteria and they agree to participate in the study the majority of sample were young aged between 15-45 years with the mean age of $31.65+/-6.79$. Shows that the majority of the study sample was house wives and completely financial dependent on their husbands, in relation to residence high percentage of the pregnant woman living in rural areas. The majority of the husbands of the abused woman were cigarettes smokers and substance abuser.

The study shows that high percentage of samples are exposed to many maternal outcome related to domestic violence such as Loss of weight before delivery $12 \%$ loss of weight while $88 \%$ not, $36 \%$ off the cases have diabetes during pregnancy while $64 \%$ not, $44 \%$ have hypertension during pregnancy while $56 \%$ not, $20 \%$ of cases have bleeding during delivery while haven't bleeding during delivery, $36 \%$ exposed to long period of delivery while $64 \%$ didn't exposed to long period of delivery, $24 \%$ exposed to premature rapture of membrane while $76 \%$ didn't exposed to premature rapture of membrane, $14 \%$ exposed to postpartum hemorrhage while $86 \%$ didn't exposed to postpartum hemorrhage. The result shows that the Percentage of domestic violence according to total domestic violence scale $82 \%$ suffer from different type of domestic violence

\section{CONCLUSION}

The present study showed that, young postpartum woman, with low socio-economic status and those who living in rural areas are much exposing to domestic violence, also woman whose husband was addicted also the study shows that financial, sexual, psychological violence was the most types of domestic violence experienced by postpartum woman that have many effect on the maternal outcome such as hypertension during pregnancy, diabetes during pregnancy and not only before delivery but it also appear during delivery such as long period of delivery, bleeding during delivery and also after delivery such as postpartum .

\section{REFERENCES}

Audi, C. A. F., Segall-Corrêa, A. M., Santiago, S. M., \& Pérez-Escamilla, R. (2012). Adverse health events associated with domestic violence during pregnancy among Brazilian women. Midwifery, 28(4), 416-421.

Bailey BA. (2010). Partner violence during pregnancy: Prevalence, effects, screening, and management. Into J Womens Health. 2:183- 97. [PMC free article] [PubMed]

Berenson, A.B., Wierman, C.M., Wilkinson G.S., Jones, W.A. \& Anderson, G.D. (2010). Perinatal morbidity associated with violence experienced by pregnant women. Journal Article Research Support, Non-US Govt. Dol: 10.1016/50029378 (94) 703523.

Black M. C., Basile K. C., Breiding M. J., Smith S. G., Walters M. L., Merrick M. T., Stevens M. R. (2011). The National Intimate Partner and Sexual Violence Survey (NISVS): 2010 Summary Report. Atlanta, GA: National Center for Injury Prevention and Control, Centers for Disease Control and Prevention. Google Scholar. 
Bhandari S., Bullock L., Bair-Merritt M., Rose L., Marcantonio K., Campbell J., Sharps P. (2012). Pregnant women experiencing IPV: Impact of supportive and nonsupportive relationships with their mothers and other supportive adults on perinatal depression: A mixed methods analysis. Issues in Mental Health Nursing, 33, 827-837. Google Scholar Medline

Chai J, Fink G, Kaaya S, Danaei G, Fawzi W, Ezzati M, et al. (2016). Association between intimate partner violence and poor child growth: results from 42 demographic and health surveys. Bull World Health Organ. 016;94(5):331-9. Epub 2016/05/06.doi: 10.2471/blt.15.152462 pmid:27147763; PubMed Central PMCID: PMCPMC4850526.

Devries K. M., Kishor S., and Johnson H. (2010). "Intimate partner violence during pregnancy: analysis of prevalence data from 19 countries," Reproductive Health Matters, vol. 18, no. 36, pp. 158- 170.

Flach C, Leese M, Heron J, Evans J, Feder G, Sharp D, et al. (2011). Antenatal domestic violence, maternal mental health and subsequent child behaviour: A cohort study. BJOG. 118:1383-91. [PubMed]

Garcia-Moreno C, Pallitto C, Devries K, Stöckl Heidi, Charlotte, Charlotte Watts, et al. (2013). Global and regional estimates of violence against women: prevalence and health effects of intimate partner violence and non-partner sexual violence. World Health Organization.

Krug EG, Mercy JA, Dahlberg LL, Zwi AB. (2012). The world report on violence and health. Lancet. 360:1083-8

Kiely M., El-MohandesAA.,Gantz MG., Chowdhury D., Thornberry JS., El-Khorazaty MN. (2011). Understanding the association of biomedical, psychosocial and behavioral risks with adverse pregnancy outcomes among African Americans in Washington, DC.Matern Child Health J.15:S85-S95 [PMC free article] [PubMed]

Negussie D., Yemane B., Ellsberg M., Emmelin M., Kullgren G., and Hogberg U. (2010). "Violence against women in relation to literacy and area of residence in Ethiopia," Global Health Action, vol. 3, p. 2070.

Effect of Domestic Violence on Pregnancy Outcomes among Rural and Urban Women DOI: 10.9790/1959-0603023542 www.iosrjournals.org 42 | Page

Nunes MA, Camey S, Ferri CP, Manzolli P, Manenti CN, Schmidt MI. (2011). Violence during pregnancy and newborn outcomes: a cohort study in a disadvantaged population in Brazil. Eur J Public Health. 21(1):92-7. Epub 2010/02/26.doi: 10.1093/eurpub/ckp241 pmid:20181682.

Rubertsson C, Borjesson K., Berglund A., Josefsson, A., Sydsjo, G. (2011). The Swedish validation of Edinburgh Postnatal Depression Scale (EPDS) during pregnancy. Nord J Psychiatry. 2011, 65 (6): 414-418. 10.3109/08039488.2011.590606. 
Shah PS. (2017). Knowledge synthesis group on determinants of preterm/LBW births. Maternal exposure to domestic violence and pregnancy and birth outcomes: A systematic review and meta-analyses. J Womens Health (Larchmt) 2010;19:203

Tejashri D., Kazi K., Y. Chavan G., Velhal, and Aras R. (2013). "Study to assess determinants of domestic violence among women in UrbanSlumofMumbai," Journal of Dental and Medical Sciences, vol. 8, no. 4, pp. 18-22.

Urquia M. L, O’Campo P. J., I. Heaman, M,. Janssen P. A, and Thiessen K. R. (2011). "Experiences of violence before and during pregnancy and adverse pregnancy outcomes: an analysis of the Canadian Maternity Experiences Survey," BMC Pregnancy and Childbirth, vol. 11, article 42, 2011.

World Health Organization (WHO): Intimate Partner Violence during Pregnancy, World Health Organization (WHO), Geneva, Switzerland, http://www.who.int/repro

Zacarias A. E., Macassa G., Svanstr"om L., Soares J. J. F., and Antai D. (2012). "Intimate partner violence against women in Maputo city, Mozambique," BMC International Health and Human Rights, vol. 12, no. 1, article 35. 